\begin{tabular}{|c|c|}
\hline Title & Unusual clinical course of preeclampsia heralded by general ized edema \\
\hline Author(s) & Kojima, T akashi; Y amada, T akahiro; Y amada, Takashi; Morikawa, Mamoru; Cho, Kazutoshi; Minakami, Hisanori \\
\hline Citation & $\begin{array}{l}\text { Journal of Obstetrics and Gynaecology Research, 39(11), 1538-1540 } \\
\text { https://doi.org/10.1111/ og.12080 }\end{array}$ \\
\hline Issue Date & $2013-11$ \\
\hline Doc URL & http:/hdl.handle.net/2115/57865 \\
\hline Rights & The definitive version is available at Wiley Online Library, www.wiley onlinelibrary.com. \\
\hline Type & article (author version) \\
\hline File Information & J Obstet Gynaecol Res_39(11)_1538_1540.pdf \\
\hline
\end{tabular}

Instructions for use 
Revised [CASE REPORTS] for JOGR

2

\section{Unusual clinical course of preeclampsia heralded by generalized edema}

4 Takahshi Kojima ${ }^{1}$, Takahiro Yamada $^{2}$, Takashi Yamada ${ }^{1}$, Mamoru Morikawa ${ }^{2}$,

$5 \quad$ Kazutoshi $\mathrm{Cho}^{2}$, Hisanori Minakami ${ }^{1}$

6

7

8 1, Department of Obstetrics, Hokkaido University Graduate School of Medicine

9 2, Hokkaido University Hospital

10

11 Running foot: Unusual preeclampsia heralded by edema

12

13

$14 *$ Corresponding author: Takahiro Yamada

15 Department of Obstetrics, Hokkaido University Graduate School of Medicine, Kita-ku

16 N14 W6, Sapporo 060-8638, Japan

17 Email: taka0197@med.hokudai.ac.jp

18

19 


\section{Abstract}

21 Background: Preeclampsia monitored by the amount of proteinuria usually does not

22 show amelioration during pregnancy.

23 Case: A 37-year-old nulliparous woman was admitted to our hospital at gestational 24 week $(\mathrm{GW}) 24^{-1 / 7}$ due to rapid weight gain $(6.2 \mathrm{~kg} / 4$ weeks $)$ and oligohydramnios. 25 Hypertension $(151 / 91 \mathrm{mmHg})$ appeared at $\mathrm{GW} 25^{-0 / 7}$ and proteinuria not detected at $26 \mathrm{GW} 24^{-0 / 7}$, became significant $(0.55 \mathrm{~g} /$ day $)$ at GW $25^{-2 / 7}$. During the two successive 27 weeks after administration of betamethasone at $12 \mathrm{mg}$ twice and transabdominal 28 amnioinfusion with $250 \mathrm{~mL}$ of Ringer's acetate solution at GW $25^{-3 / 7}$, generalized 29 edema, proteinuria, and thrombocytopenia markedly improved: body weight, 78.0 $3069.0 \mathrm{~kg}$; proteinuria (g/day), $7.1-1.3$; and platelet count $\left(\times 10^{9} / \mathrm{L}\right), 111-230$. However, 31 intrauterine infection accompanied by non-reassuring fetal status necessitated 32 emergency cesarean section at GW $28^{-3 / 7}$.

33 Conclusion: Extrordinary body weight gain can herald the occurrence of 34 preeclampsia and this weight gain together with signs of preeclampsia can ameliorate even during pregnancy, although its mechanism is unclear.

37 Keywords: gestational edema, preeclampsia, thrombocytopenia, vascular permeability 


\section{Introduction}

40 Women with preeclampsia are likely to show excessive water retention [1]. Although 41 generalized edema can precede the development of preeclampsia [2], there is as yet no 42 technical term applicable to the condition of edema alone. Preeclampsia usually does 43 not show amelioration during pregnancy. Here, we present a pregnant woman in whom preeclampsia was heralded by generalized edema and clinical signs of preeclampsia acutely ameliorated during pregnancy.

\section{Presentation of the case}

This study was approved by the institutional review board of the Hokkaido University Hospital and was undertaken following the provisions of the Declaration of Helsinki.

50 A 37-year-old nulliparous Japanese woman presented with marked edema (weight gain of $6.2 \mathrm{~kg} / 4$ weeks) (Fig. 1) and oligohydramnios (amniotic fluid index [AFI] of $4.8 \mathrm{~cm}$ ) in the absence of hypertension, proteinuria, or placental edema and was admitted to our hospital at gestational week $(\mathrm{GW}) 24^{-1 / 7}$. Hypertension $(151 / 91 \mathrm{mmHg})$ and proteinuria (0.55 g/day) appeared at $\mathrm{GW} 25^{-0 / 7}$ and $\mathrm{GW} 25^{-2 / 7}$, respectively. Primary aldosteronism, autoimmune diseases, or thyroid diseases were considered unlikely by endocrinologists and immunologists (Table 1). Administration of betamethasone for fetal lung maturation (intramuscular $12 \mathrm{mg}$ twice) and amnioinfusion with $250 \mathrm{~mL}$ of Ringer's acetate solution for oligohydramnios (AFI of $0.4 \mathrm{~cm}$ ) were performed at $\mathrm{GW}$ $25^{-3 / 7}$ (Fig. 1). An AFI of $11.5 \mathrm{~cm}$ at GW $25^{-4 / 7}$ gradually decreased to $3.8 \mathrm{~cm}$ at GW $27^{-6 / 7}$. Treatment with oral nifedipine (20 mg/day) was initiated at $\mathrm{GW} 26^{-0 / 7}$. The

61 maternal body weight began to decrease after showing a peak value at GW $25^{-5 / 7}$ and 62 platelet counts began to increase after showing a nadir value at GW $26^{-6 / 7}$, while 
hematocrit values were stable (Fig. 1). Proteinuria (g/day) also began to decrease after showing a peak value of 7.1 at GW $26^{-6 / 7}$ to 1.3 at GW $27^{-3 / 7}$, respectively, while blood pressure remained high $(140-170 / 75-95 \mathrm{mmHg})$.

Four days after the second amnioinfusion ( $250 \mathrm{~mL}$ of Ringer's acetate solution) at $\mathrm{GW}$ $27^{-6 / 7}$ for oligohydramnios (AFI of $3.8 \mathrm{~cm}$ ), the patient exhibited fever of $38.6^{\circ} \mathrm{C}$ with elevated C-reactive protein level $(5.7 \mathrm{mg} / \mathrm{dL})$ and WBC count $(20200 / \mu \mathrm{L})$, as well as non-reassuring fetal status at GW $28^{-3 / 7}$. A growth restricted (-1.45 SD) female infant weighing $820 \mathrm{~g}$ was born by emergency cesarean section. Pathological examination of the placenta revealed chorioamnionitis (stage III). The infant survived septicemia with Abiotrophia defectiva and left our hospital on hospital day 85. Magnetic resonance imaging (MRI) of the infant's brain performed on hospital day 82 was unremarkable. The mother leaving our hospital on postpartum day 8 showed normal blood pressure $(127 / 69 \mathrm{mmHg})$ and non-significant proteinuria (negative on dip stick test) at 1 month postpartum.

\section{Discussion}

This patient exhibited two unusual features of pregnancy. First, her preeclampsia was heralded by extraordinary weight gain between GW 20 and 24 . Second, her preeclampsia monitored by changes in body weight (degree of edema), proteinuria, and platelet counts showed amelioration during pregnancy.

We previously encountered a woman who exhibited rapid weight gain $(6.0 \mathrm{~kg}$ in the last 7 days of pregnancy) with gradual declines in antithrombin activity and platelet count until delivery [2]. In this previous case, the risk of pulmonary edema necessitated cesarean section at GW 37 in the absence of hypertension and proteinuria, and 
87 pulmonary edema actually developed postpartum followed by hypertension, but the 88 diagnosis of preeclampsia had to wait until 5 days after delivery at which time 89 proteinuria developed [2]. Thus, a type of preeclampsia with edema as its initial sign 90 indeed exists. The present case also showed a gradual decline in platelet count (Fig. 1) 91 and modestly reduced antithrombin activity (72\% of normal activity level). Pregnant 92 women with reduced antithrombin activity and/or platelet counts are suggested to be 93 suffering from increased blood vessel permeability [3, 4]. The appearance of edema is 94 likely a consequence of endothelial leakage of plasma into the interstitial space. 95 Consequently, plasma volume is reduced by approximately $20 \%$ in women with 96 preeclampsia [5] and more in women with eclampsia [6]. The rapid and extraordinary 97 weight gain in our patient may be explained by the same mechanism as that in women 98 with preeclampsia.

100 Amounts of protein in the urine increase with advancing gestation irrespective of the 101 presence or absence of hypertension [7]. In the presence of increased blood vessel 102 permeability, adequate water intake results in edema formation with stable hematocrit 103 value, but insufficient water intake results in increased hematocrit value, and finally a 104 decrease in body weight designated as "dehydration." Thus, in the presence of increased 105 blood vessel permeability, maternal body weight is unlikely to decrease in the absence 106 of changes in hematocrit value. However, the present case exhibited marked weight 107 reduction with stable hematocrit value and a decrease in proteinuria. As the period until 108 delivery after the diagnosis of preeclampsia is approximately 2 weeks [7], this patient 109 received steroid administration and amnioinfusion, resulting in an increase of AFI from 1100.4 to $11.5 \mathrm{~cm}$. It remains unclear whether these treatments contributed to the favorable 
Kojima et al.

111 changes in various parameters seen in this patient.

112

\section{Disclosure}

114 All authors declare that they have no financial relationship with a biotechnology

115 manufacturer, a pharmaceutical company, or other commercial entity that has an interest

116 in the subject matter or materials discussed in the manuscript.

117

118 


\section{Kojima et al.}

\section{References}

1. Thomson AM, Hytten FE, Billewicz WZ. Epidemiology of oedema during pregnancy. J Obstet Gynaecol Br Commonwealth 1967;74:1-10.

2. Koyama T, Yamada T, Morikawa M, Tanaka R, Yamamura M, Araki N, et al. Marked gestational edema as a clinical sign of life-threatening condition. J Obstet Gynaecol Res. 2010;36:861-5.

3. Morikawa M, Yamada T, Yamada T, Shimada S, Koyama T, Cho K, et al. Pregnancy-induced antithrombin deficiency. J Perinat Med. 2010;38:379-85.

4. Minakami H, Morikawa M, Yamada T, Yamada T. Candidates for the determination of antithrombin activity in pregnant women. J Perinat Med. 2011;39:369-74.

5. Silver HM, Seebeck MA, Carlson R. Comparison of total blood volume in normal, preeclamptic, and nonproteinuric gestational hypertensive pregnancy by simultaneous measurement of red blood cell and plasma volumes. Am J Obstet Gynecol 1998;179:87-93.

6. Zeeman GG, Cunningham FG, Pritchard JA. The magnitude of the hemoconcentration in preeclampsia. Hypertens Preg. 2009;28:127-37.

7. Morikawa M, Yamada T, Yamada T, Cho K, Yamada H, Sakuragi N, et al. Pregnancy outcome of women who developed proteinuria in the absence of hypertension after mid-gestation. J Perinat Med. 2008;36:419-24. 
Kojima et al.

\section{$140 \quad$ Figure Legend}

141 Figure 1: Changes in maternal body weight $(\circ)$, platelet counts $(\bullet)$, and hematocrit 142 value $(x)$

143 PPD, postpartum day 


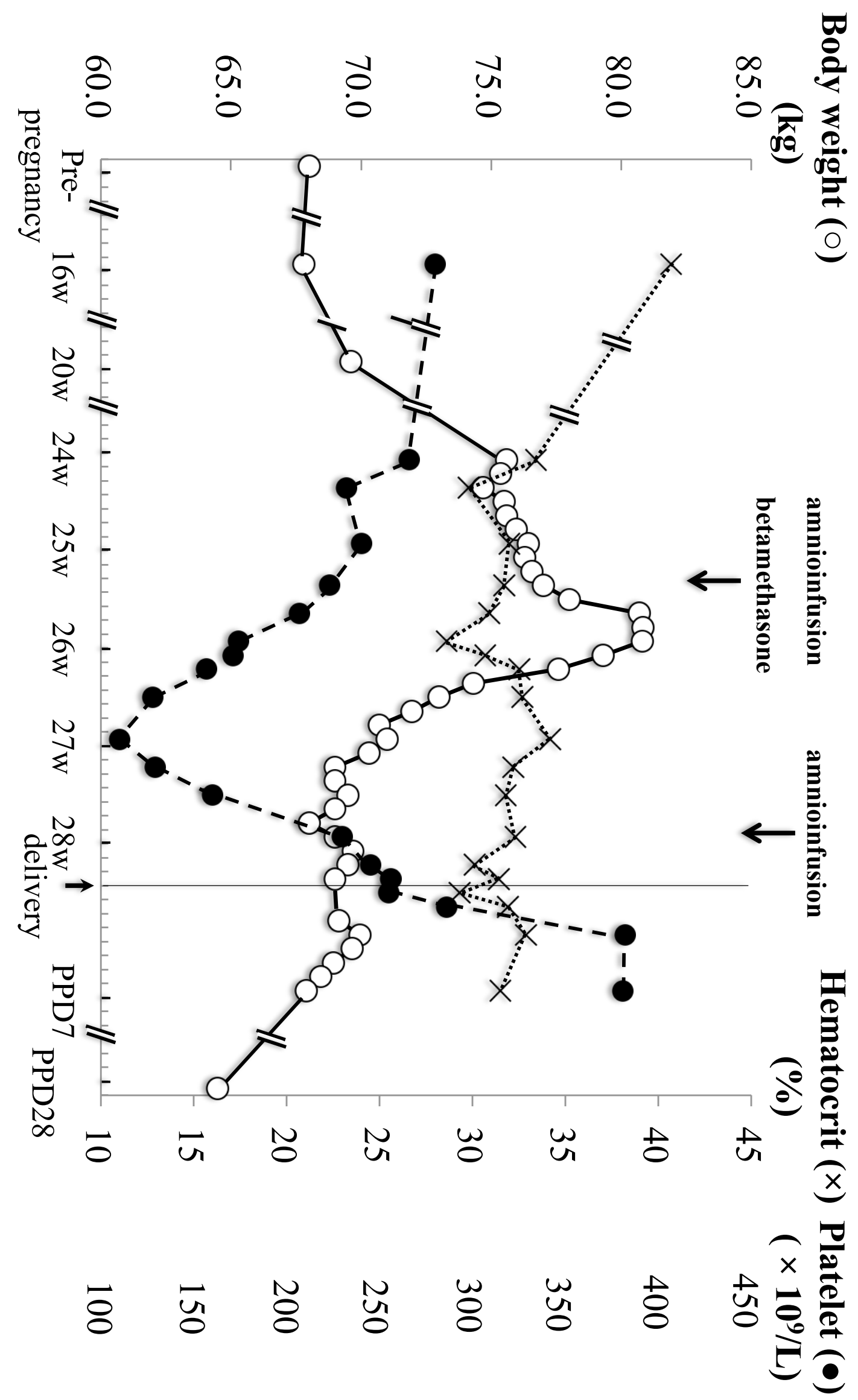


Table 1. Results of laboratory work-up and Doppler study

Antithrombin activity [\% of normal activity level]; $78\left(24^{-0 / 7}\right), 72\left(25^{-2 / 7}\right), 86\left(27^{-6 / 7}\right)$

AST [IU/L]; $12\left(24^{-0 / 7}\right), 13\left(28^{-3 / 7}\right), 16$ (PPD 3); LDH (IU/L), $161\left(24^{-0 / 7}\right), 137\left(28^{-3 / 7}\right), 190$ (PPD 3)

PAC [ng/L]; $124\left(24^{-6 / 7}\right), 115\left(26^{-0 / 7}\right)$ : PRA [ng/mL/hour]; $2.8\left(24^{-6 / 7}\right), 2.7\left(26^{-0 / 7}\right)$

$\mathrm{TSH} ; 2.16 \mu \mathrm{IU} / \mathrm{mL}\left(24^{-6 / 7}\right)$ : Free T4; $1.1 \mathrm{ng} / \mathrm{dL}\left(24^{-6 / 7}\right)$

NT-proBNP [ng/L]; $992\left(26^{-0 / 7}\right), 79\left(27^{-6 / 7}\right)$

$\operatorname{IgA} ; 147 \mathrm{mg} / \mathrm{dL}\left(24^{-2 / 7}\right): \quad \operatorname{IgG} ; 735 \mathrm{mg} / \mathrm{dL}\left(24^{-2 / 7}\right): \quad \operatorname{IgM} ; 186 \mathrm{mg} / \mathrm{dL}\left(24^{-2 / 7}\right):$

$\operatorname{IgE} ; 107 \mathrm{mg} / \mathrm{dL}\left(24^{-2 / 7}\right)$

$\mathrm{C} 3 * ; 95 \mathrm{mg} / \mathrm{dL}\left(24^{-2 / 7}\right): \mathrm{C} 4^{*} ; 7 \mathrm{mg} / \mathrm{dL}\left(24^{-2 / 7}\right): \mathrm{CH} 50 * ; 31 \mathrm{U} / \mathrm{mL}\left(24^{-2 / 7}\right)$

Rheumatoid factor; $0.9 \mathrm{IU} / \mathrm{mL}\left(24^{-2 / 7}\right)$ : Antinuclear antibody; negative $\left(24^{-2 / 7}\right)$

Anti-cardiolipin antibody; ND $\left(25^{-2 / 7}\right)$ : Lupus anticoagulant; ND $\left(25^{-2 / 7}\right)$

Anticardiolipin- $\beta 2$ glycoprotein I complex antibody; ND $\left(26^{-1 / 7}\right)$

Umbilical artery pulsatility index; $1.52\left(25^{-2 / 7}\right), 0.99\left(28^{-2 / 7}\right)$

Umbilical artery resistance index; $0.76\left(25^{-2 / 7}\right), 0.65\left(28^{-2 / 7}\right)$

Fetal middle cerebral artery pulsatility index; $1.27\left(25^{-2 / 7}\right), 1.30\left(28^{-2 / 7}\right)$

Fetal middle cerebral artery resistance index; $0.73\left(25^{-2 / 7}\right), 0.74\left(28^{-2 / 7}\right)$

Gestational week at examination is indicated in parenthesis.

PPD 3, postpartum day 3; AST, Aspartate aminotransferase; LDH, Lactate dehydrogenase;

PAC, plasma aldosterone concentration; PRA, plasma renin activity; TSH, thyroid stimulating hormone;

NT-proBNP, N-terminal fragment of precursor protein brain-type natriuretic peptide;

Ig, Immunoglobulin; *, Complement; ND, not detected 